\title{
Hearing restoration: \\ Graeme Clark, Ingeborg Hochmair, and Blake Wilson receive the 2013 Lasker DeBakey Clinical Medical Research Award
}

\begin{abstract}
Living in a world of silence can be isolating and lonely for those who have lost their hearing or were born deaf. When results from early seminal studies provided hope that a device could restore hearing to the deaf through electrical stimulation of the auditory nerve, many experts adamantly disagreed that hearing could be restored in a meaningful way. Fortunately, many dedicated individuals ignored these detractors and committed themselves to the development of such a device. The 2013 Lasker DeBakey Clinical Medical Research Award honors Graeme Clark, Ingeborg Hochmair, and Blake Wilson (Figure 1), three visionaries who have contributed greatly to development of the modern cochlear implant. This device has brought a world of sound and improved the quality of life for hundreds of thousands of people since its inception.
\end{abstract}

\section{Sound: what's in a wave?}

The process of hearing was little more than a phenomenon in 1930, when Ernest Wever and Charles Bray performed experiments to understand how sound input at the ear translates to hearing in the brain. From their results, Wever and Bray determined that sound applied to the ear of a cat produces a response in the auditory nerve, corresponding to the frequency and tone of the input sound. Their investigation also revealed that cochlear loss or damage prevented development of electrical impulses in the auditory nerve. This study provided some of the first evidence that electrical impulses could replicate sound and restore hearing. Furthermore, they demonstrated that the structures of the inner ear were essential for sound transmission (1).

Over two decades later, in 1957, the French otolaryngologist Charles Eyriès implanted an electrode designed by physiologist André Djourno into a patient who only had the stumps of both auditory nerves remaining after multiple ear surgeries. The electrode was placed directly into one of the auditory nerve stumps. Initial tests revealed that electrical stimuli generated from a microphone were detectable and the patient was able to distinguish inputs of different intensities; however, sound frequencies were difficult to distinguish. The patient was unable to understand natural speech or tell individual voices apart (2). Ultimately, the device failed and had to be removed several weeks after implantation, but the work had far-reaching effects, inspiring a wave of implant development.

Several major breakthroughs occurred during the 1960s. After a patient presented him with an article in the Los Angeles Times about the results from Djourno and Eyriès, William House, a Los Angeles-based otologist, began his journey into electrically evoked hearing. In 1961, he recruited neurosurgeon John Doyle to implant a group of patients with a single wire each. These implants were inserted a short distance into the cochlea through the round window membrane $(3,4)$. The initial results were promising. Patients had some frequency discrimination and could identify some words in closed-set hearing tests, which limit the possible responses, but were unable to understand speech. Meanwhile, at Stanford University, Blair Simmons and coworkers implanted multiple wires attached to different electrodes into the auditory nerve of a patient. Electrical access to the electrodes was provided via a percutaneous plug, by which the electrodes could be individually stimulated. Studies with this patient found that perceived pitch could be varied through changing the electrode that was stimulated. This was some of the first evidence to indicate that the location (or place) of stimulation in the cochlea was important for the perception of pitch (Figure 2). Despite initial promise, the patient was not able to understand speech (5). Even though the results for these initial implantation studies were encouraging, many detractors in the scientific and medical communities actively spoke out against the use and feasibility of these devices to restore hearing. Undeterred, House would go on to partner with electrical engineer Jack Urban to create a single-channel implant that could be used outside of the lab and remain implanted
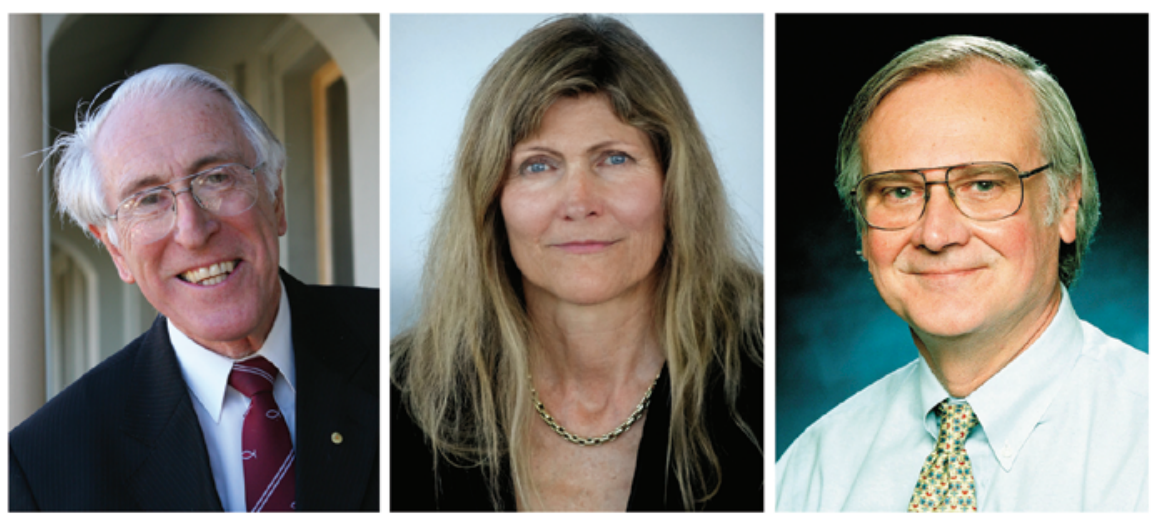

\section{Figure 1}

The recipients of the 2013 Lasker DeBakey Clinical Medical Research Award. Graeme Clark (left) of the University of Melbourne, Ingeborg Hochmair (center) of MED-EL, and Blake Wilson of Duke University (right) have been honored for their contributions to the development of the modern cochlear implant. 


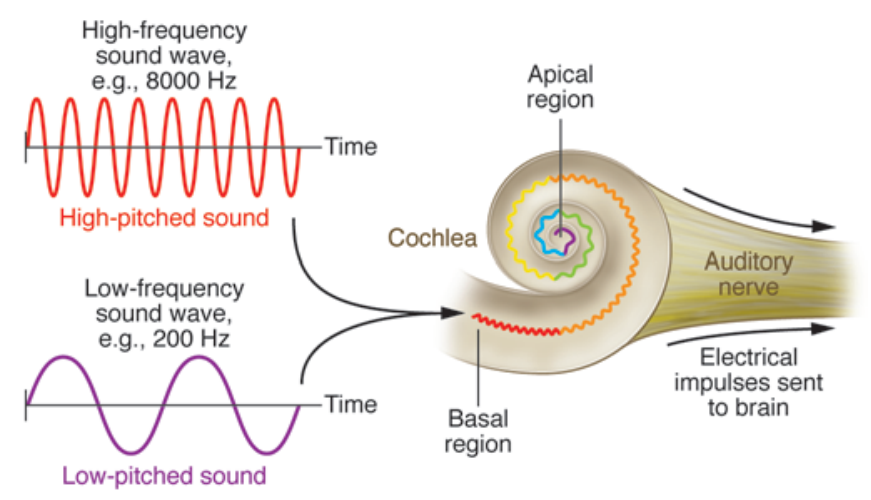

\section{Figure 2}

Place coding in the cochlea is important for sound frequency (pitch) discrimination. Perceived pitch of a sound depends on the location in the cochlea that the sound wave stimulated. High-frequency sound waves, which correspond to high-pitched noises, stimulate the basal region of the cochlea (red). Low-frequency sound waves are targeted to the apical region of the cochlear structure and correspond with low-pitched sounds (purple). Therefore, it is important for the cochlear implant electrode array to provide stimuli at multiple positions along the length of the cochlea. for a long period of time (3). Simmons discontinued his work on humans for several years to focus on experimental animal models to study the physiological responses to electrical stimuli and evaluate implantation safety (6-9); however, he too would return to working directly with human patients.

\section{Dawn of the modern cochlear implant}

During the time Simmons was conducting his experiments, a young Australian surgeon, Graeme Clark, was moving up the ranks at the Royal Victorian Eye and Ear Hospital as an ear, nose, and throat (ENT) surgeon. Clark had first-hand experience with the consequences of hearing loss, watching his father struggle to communicate as his hearing declined with age. He recently recalled his reaction to Simmons' research to the JCI: "I was motivated by Blair Simmons... he got some sound sensations but no speech understanding. For an inexplicable reason, this lit a fire in my belly. I always wanted to do research; that was something that drove me." $\mathrm{He}$ soon left his position at the Royal Victorian Eye and Ear Hospital to pursue a $\mathrm{PhD}$ in neurophysiology. His dissertation research focused on the role of the middle ear structure in transmitting sound and the responses in the brain $(10,11)$. Much of Clark's early research was done in a cat model. "I didn't want to do things on my patients unless I had a good grounding on the possibility it would work for them." Using the cat, he measured the action potentials of individual and groups of neurons while varying the rate at which electrical impulses were delivered to the auditory brain stem (12). The cat and human temporal bones also became an important model for the development of the intricate surgical techniques that would be required to implant a device safely in human patients.

The 1970s would see the development of implantable devices from several groups around the world. At UCSF, a team that included otologist Robin Michelson and neurophysiologist Michael Merzenich, among others, implanted a group of patients with a single electrode implant each (13). The results from these patients were similar to those reported by House. Patients could distinguish among some frequencies and differentiate among signal intensities, but they did not understand speech (14).

While early experiments were being conducted in California, a young engineer at the Research Triangle Institute (RTI) in North Carolina, Blake Wilson, was just beginning his foray into hearing research. As he recently recalled to the JCI, "I had a project where I was an assistant to build a device to help deaf people disambiguate the ambiguities of lip reading. That project involved some fairly sophisticated speech analysis and also made me keenly aware of the problems of deaf and severely hearing impaired persons.” In 1977, Wilson would receive a grant that allowed him to visit the three centers in California where the House, Simmons, and Merzenich teams were actively involved in the development and first applications for their implant devices. "The purpose was for me to learn more about what these folks were doing and also to see if I or others at the institute could possibly help in some way, maybe in the area of speech analysis."

At the Technical University of Vienna, surgeon Kurt Burian, head of the ENT clinic, recruited his collaborator, electrical engineer Erwin Hochmair, who in turn enlisted the first Austrian woman to earn a $\mathrm{PhD}$ in electrical engineering, his future wife, Ingeborg Hochmair (née Desoyer) to the project. In a recent interview with the $J C I$, Ingeborg Hochmair recalled the inspiration for the project: "Professor Burian went to the House [Research] Institute early on and saw the early House device, which was a simple device that worked like a transformer. He came back from that conference and asked my husband to build an implant for him.” The system they designed consisted of an implantable unit and an external device. The internal component included eight electrodes that were implanted into the cochlea, which was connected to a receiver/stimulator implanted under the skin. Acoustic information received through a microphone went into an eight-channel processing unit that generated electrical stimulation parameters, which then went to the transmitter. The transmitter then sent this information to the receiver/stimulator via a transcutaneous link (15). Their device was implanted in a deaf patient on December 16, 1977.

After completing his $\mathrm{PhD}$, Clark returned to the University of Melbourne as the chair of otolaryngology. His research on hearing in animal models prepared him for the task of developing his first cochlear implant device. Like the Burian and Hochmair group, Clark knew that for a device to be able to stay in place for a long period of time, the stimulating unit would need to be subcutaneous. "If it had been a plug and socket, we would have had quite a lot of flexibility to explore different ways of stimulating the brain, but we had to make that decision. I think it was the right thing to do, minimize infection," Clark recalled. His research also indicated that the location within the cochlea was important for pitch perception. His first implant had an array of 20 electrodes that were inserted directly into the cochlea and connected to a subcutaneous receiver/stimulator unit. The Melbourne group's receiver/stimula- 


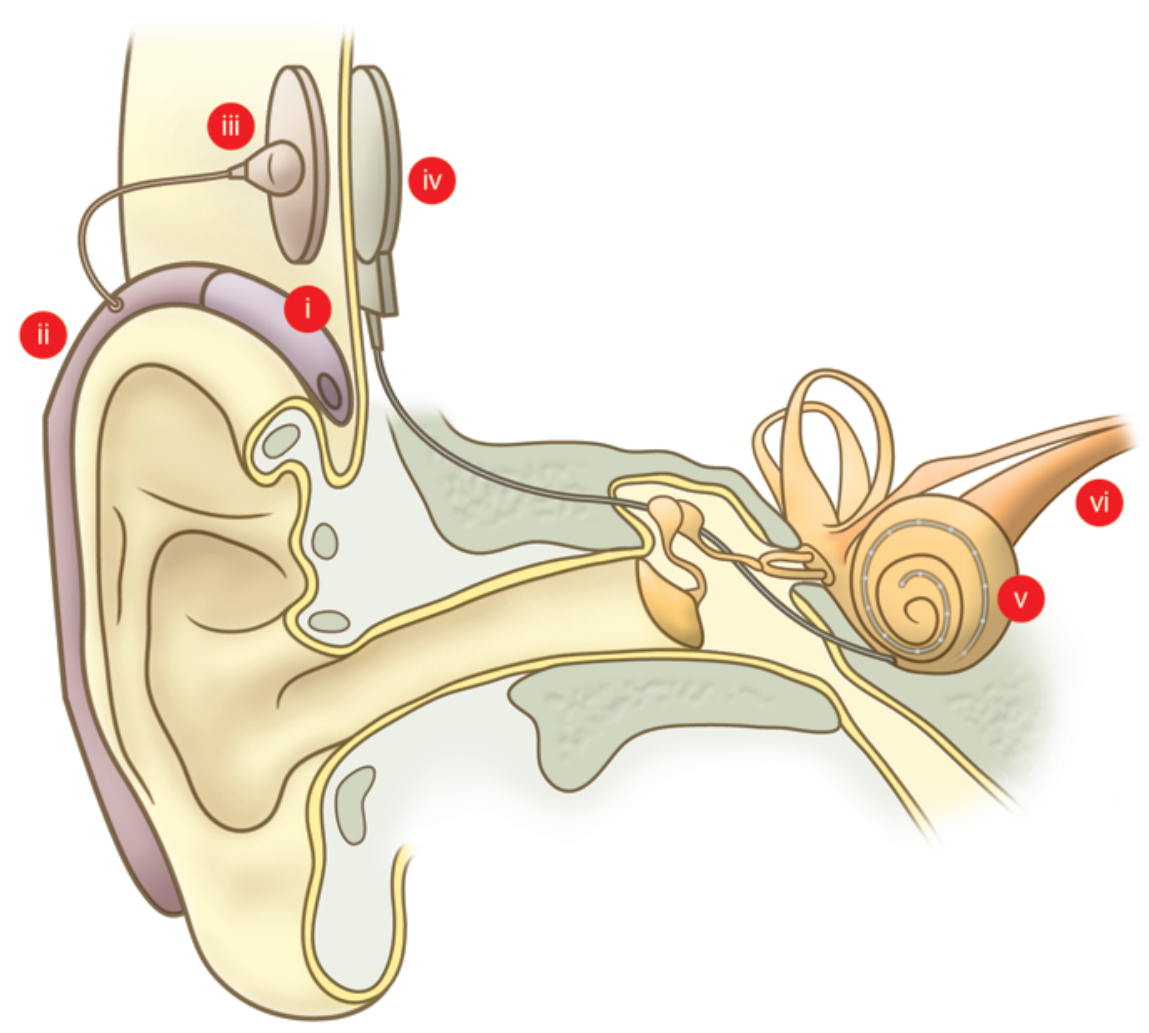

tor received signals transmitted from an external ten-channel processing unit. The first implantation of their device into a deaf patient was on August 1, $1978(10,11)$.

\section{From silence to sound}

Before either of the Vienna or Melbourne devices could be tested, the teams at the respective cities had to wait for the patients to recover from their surgeries. There was much anxiety and excitement during the wait to connect the implants with the external processing units. Ingeborg Hochmair describes the patients coming back to the center in Vienna after recovering from surgery: "It was very emotional when these patients came to the test room. The test room was at the Technical University, [and the patients were] hooked up to the test system and could hear, but of course we did not start with speech. It was bursts of pulses. The good thing was they could identify the channels and discriminate between them." Emotions were also running high for the Melbourne group as they prepared to test their device. Clark explained to the JCI, "The first time we were quite anxious, all our small group of clinicians and psychologists, psychophysicists, and engineers; we were just on tenterhooks, you might say, to see if it worked.
Would all of this effort produce something that would work?" They brought their patient, Rod Saunders, to the lab for testing, lined up the external unit with the internal receiver-stimulator, turned on the device, and nothing happened. A second attempt to turn on the device several days later would also prove disappointing. "It was even more disappointing the second time it didn't work, but it was fortunate that one learns to be thorough in research and engineering. The engineer in charge found a loose connection, and so we were absolutely thrilled about this loose connection because then it gave hope. Sure enough, when he came back and they fixed the loose connection, he started to hear this other sound when the signal was put on. He had very bad head noises from his head injury. So at first we and he weren't sure whether this was a new sound, but this was a new sound for him and it got louder and louder and that was great," Clark said. Exploring how these patients perceived electrical impulses confirmed that perception of pitch depends on the site of stimulation within the cochlea (Figure 2).

The willing participation of these early implant recipients was key to the further development of the speech-processing units. Implant recipients have been instru-

\section{Figure 3}

The modern cochlear implant. Sound is detected by the microphone (i), which in this illustration is integrated into a behind-theear processing unit (ii). The processing unit translates sound into a digital signal that is passed from the transmitter (iii) to the internal receiver stimulator (iv). The receiver stimulator decodes sound information from the processing unit into electric stimuli that are delivered to the cochlea via an electrode array (v). Electric signals from the cochlea are transmitted to the brain by the auditory nerve (vi). mental in and dedicated to the testing and experimentation that is required to fine-tune the speech code. The Melbourne team used a careful, systematic approach to understand how the signals generated from the sound processor were translated to sound. Speaking of the sensations produced by the individual electrodes in the ear, Clark recalled, "They were different, the sound sensations were different. And that was one of the features of our research, to put the question of speech coding together from understanding the sensations that he got from the individual electrodes because it was all based on ultimately place coding." The Austrian team would also find a dedicated volunteer, who along with her siblings had gone deaf. Ingeborg Hochmair recollects, "We were so lucky to have this one patient in particular, Connie, who moved to Vienna from Germany. She said, "Here, my brother and I went deaf. I want to help with the development of [this device]." She wrote a letter to Burian stating, "If you implant me, I will come to your lab every day and I will help." Both Rod Saunders and Connie would go on to understand speech with their cochlear implants and are long-time users of the device. Connie, in particular, understood speech without lip reading via 
a small body-worn processor in 1979 and has continued to do so ever since (16). The basic design concepts of these first devices are still in use today (Figure 3).

\section{Cracking the speech code}

In 1988, the United States' NIH convened a consensus development conference on cochlear implants. At this point, a few thousand patients had received implants, and the consensus resulting from the conference was that about one out of every twenty implanted patients could take part in a conversation without lip reading (17). It was around this time that speech-processing strategies would take a major step forward.

Soon after the NIH report, Wilson and his group at the RTI invented a new approach to sound processing for cochlear implants that utilized the multiple sites of stimulation in the cochlea far better than before. Unlike some prior strategies, this new strategy did not extract and then represent specific features from the input, and unlike some other prior strategies, the new strategy did not stimulate electrodes simultaneously, but instead, stimulated them sequentially with brief pulses. The removal of the feature extraction allowed the representation of at least a substantial fraction of the information that could be perceived with electrical stimulation of the auditory nerve, and the nonsimultaneous stimulation eliminated a major component of spurious interaction or "cross talk" among electrodes that, if present, degraded perception of the "place of stimulation" cues substantially. This strategy, called "continuous interleaved sampling" (CIS), combined the best aspects of disparate prior strategies and added some new elements as well (18).

Evaluation of CIS commenced in 1989. "What we did was to compare this new strategy with the very best of what had been developed before. These subjects had the very best performance that could be achieved with a cochlear implant. Each subject demonstrated tremendous, immediate improvement with the application of this new processing strategy," said Wilson. CIS is still in widespread clinical use today, and it has been the basis of many processing strategies developed subsequently. Improvements in processing strategies and other elements of cochlear implant systems developed by the RTI teams have also been dependent on the dedication of implanted volunteers. Blake Wilson is especially grateful, for example, for the endless time put in by Michael Pierschalla in his service as a research subject, "He was one of the most intelligent and articulate people I ever met. He was a musician before he lost his hearing. He had a fabulous vocabulary to describe what he heard through the implant. What he told us often surprised us. It was those surprises that led to the sparks to move forward."

Before CIS, the majority of patients that had success with a cochlear implant could previously hear and had developed the pathways for hearing in the brain. The vast improvements in speech processing with the CIS and subsequent strategies has now made it possible for children who are born deaf to receive a cochlear implant and learn to recognize and produce speech. It is important for deaf children to be implanted at an early age, while the brain still has plasticity for speech development (19).

One of the most impressive aspects of the advancements in speech-processing strategies has been the goal of cochlear implant companies to design their new external units to function with older implants. With the possibility that an implant will be with patients for their entire lives, these processor upgrades will serve to continuously improve speech recognition, reduce background noise, and fine tune the translation of sound waves into meaningful electrical signals without the need for additional surgery (20-24). Of one of the initial Austrian implant recipients, Ingeborg Hochmair informed the JCI, "She has been enjoying open speech understanding without lip reading with a cochlear implant now for 34 years. This is for the longest time recorded so far, and I think for implant candidates this is really good to know. It works for such a long time, and she only got better with the upgrades in the speech processors.”

\section{The future of hearing}

Clark has never ceased in his pursuit to provide perfect hearing for patients. Even today, he is looking to the future of cochlear technology with help from his first implant patient, as Clark recently discussed with the JCI: "My first patient, Rod Saunders, was so committed that, when he died, he donated his [temporal] bones for research. I have found that by studying his temporal bones, I have discovered many things that I never expected, using the latest technologies. This is showing the fine network of nerves in his ear much more clearly than any other procedure. On the one hand, I have this data showing how nerves were connected [to the electrode array]; I've got data from our clinic work with him showing what he perceived when stimulating these electrodes some years ago. I am now trying to put this together so that we will understand better how to electrically stimulate people's ears to give them the sensations that will give them better speech understanding."

Implant research and design require a forward-looking approach. As Ingeborg Hochmair told the JCI, "The features of cochlear implants that are turning out to be really important are the hearing and structure preservation topics. The electrodes have to be long and flexible, such that they don't do any damage... If you implant a child now, around the age of one, they might live 120 years. So many other therapies may come up that we have no idea about. You don't want to prevent these children from profiting from other treatments. You want to preserve the structure, even if there is no hearing left." Even more important for the future of cochlear implantation is providing access to those that would most benefit from implantation. Hochmair is passionate about this topic. "I really think you should get a cochlear implant if you are a candidate for it. As a deaf child or a child who became deaf early in life, this is connected to a human right for education. If you need a cochlear implant for your education, you should get it. The fact that this is not the case for many countries and circumstances is sad. It needs to be worked on."

Expansion of cochlear implant technology is also an important goal for Wilson. As he explained to the JCI, "A deaf child who receives a cochlear implant early in life can be mainstreamed into public schools and perform on par with his or her peers. The great majority of persons who have been deaf all their lives have not attained more than a third- or fourth-grade level of education. This is a tremendous tragedy, and that tragedy is greatly multiplied in low- to mid-income countries. It's not purely or mostly a technology problem; it is a distribution and awareness problem.” Providing cochlear implants to deaf individuals in developing countries is an issue that, much like the development of cochlear implants, will require dedication and collaboration.

The realization of the cochlear implant was truly made possible through the dedication, perseverance, and open collaboration among countless scientists, clinicians, surgeons, engineers, patients, and research 
groups. The contributions of Graeme Clark, Ingeborg Hochmair, and Blake Wilson are heard every day by the thousands of individuals that are currently benefitting from this device.

\section{Corinne Williams}

1. Wever EG, Bray CW. The nature of acoustic response: The relation between sound frequency and frequency of impulses in the auditory nerve. J Exp Psychol. 1930;13(5):373-387.

2. Djourno A, Eyries C. [Auditory prosthesis by means of a distant electrical stimulation of the sensory nerve with the use of an indwelt coiling]. Presse Med. 1957;65(63): 1417 .

3. House WF, Urban J. Long term results of electrode implantation and electronic stimulation of the cochlea in man. Ann Otol Rhinol Laryngol. 1973; 82(4):504-517.

4. House WF. Cochlear implants. Ann Otol Rhinol Laryngol. 1976;85 suppl 27(3 pt 2):1-93.

5. Simmons FBF. Electrical stimulation of the auditory nerve in man. Arch Otolaryngol. 1966;84(1):2-54.

6. Eshraghi AA, Nazarian R, Telischi FF, Rajguru SM, Truy E, Gupta C. The cochlear implant: historical aspects and future prospects. Anat Rec (Hoboken). 2012;295(11):1967-1980

7. Simmons FB, Beatty DL. Sound field variability: Some measurements from the cat. Electroencephalogr Clin Neurophysiol. 1964;17:332-334.
8. Simmons FB, Beatty DL. Habituation (adaptation) in the middle-ear muscle reflexes of the cat. Acto Otolaryngol. 1964;57:89-96.

9. Simmons FB. Permanent intracochlear electrodes in cats, tissue tolerance and cochlear microphonics. Laryngoscope. 1967;77(2):171-186.

10. Clark GM. Personal reflections on the multichannel cochlear implant and a view of the future. J Rehabil Res Dev. 2008;45(5):651-694.

11. Clark GM. The multiple-channel cochlear implant: the interface between sound and the central nervous system for hearing, speech, and language in deaf people-a personal perspective. Philos Trans R Soc Lond B Biol Sci. 2006;361(1469):791-810.

12. Clark GM. Responses of cells in the superior olivary complex of the cat to electrical stimulation of the auditory nerve. Exp Neurol. 1969;24(1):124-136.

13. Merzenich MM, Michelson RP, Pettit CR, Schindler RA, Reid M. Neural encoding of sound sensation evoked by electrical stimulation of the acoustic nerve. Ann Otol Rhinol Laryngol. 1973;82(4):486-503.

14. Michelson RP, Merzenich MM, Pettit CR, Schindler RA. A cochlear prosthesis: further clinical observations; preliminary results of physiological studies. Laryngoscope. 1973;83(7):1116-1122.

15. Hochmair ES, Hochmair-Desoyer IJ. An implanted auditory eight channel stimulator for the deaf. Med Biol Eng Comput. 1981;19(2):141-148.

16. Hochmair-Desoyer IJ, Hochmair ES, Burian K, Fischer RE. Four years of experience with cochlear prostheses. Med Prog Technol. 1981;8(3):107-119.

17. US Department of Health and Human Services. National Institutes of Health Consensus Develop- ment Conference Consensus Statement. May 2-4, 1988. NIH Web site. http://consensus.nih.gov/1988/ 1988CochlearImplants068html.htm. Accessed August 26, 2013.

18. Wilson BS, Finley CC, Lawson DT, Wolford RD, Eddington DK, Rabinowitz WM. Better speech recognition with cochlear implants. Nature. 1991;352(6332):236-238.

19. Niparko JK, et al. Spoken language development in children following cochlear implantation. JAMA. 2010;303(15):1498-1506.

20. Mosnier I, Marx M, Venail F, Loundon N, RouxVaillard S, Sterkers O. Benefits from upgrade to the CP810 sound processor for Nucleus 24 cochlear implant recipients [published online ahead of print: February 14, 2013]. Eur Arch Otorbinolaryngol. doi:10.1007/s00405.013.2381-8.

21. Seebens Y, Diller G. Improvements in speech perception after the upgrade from the TEMPO+ to the OPUS 2 audio processor. ORL J Otorbinolaryngol Relat Spec. 2012;74(1):6-11.

22. Lorens A, Zgoda M, Obrycka A, Skarzynski H. Fine Structure Processing improves speech perception as well as objective and subjective benefits in pediatric MED-EL COMBI 40+ users. Int J Pediatr Otorbinolaryngol. 2010;74(12):1372-1378.

23. Müller-Deile J, Kortmann T, Hoppe U, Hessel H, Morsnowski A. [Improving speech comprehension using a new cochlear implant speech processor]. HNO. 2009;57(6):567-574.

24. Cohen NL, et al. Results of speech processor upgrade in a population of Veterans Affairs cochlear implant recipients. Am J Otol. 1997;18(4):462-465. 